\title{
Bee pollen as a natural antioxidant source to prevent lipid oxidation in black pudding
}

\author{
Ofélia Anjos $^{\mathrm{a}, \mathrm{b}, \mathrm{c}, *}$, Rodrigo Fernandes ${ }^{\mathrm{a}}$, Susana M. Cardoso ${ }^{\mathrm{d}}$, Teresa Delgado ${ }^{\mathrm{c}}$, Nelson Farinha ${ }^{\mathrm{c}}$, \\ Vanessa Paula ${ }^{f}$, Letícia M. Estevinho ${ }^{e}$, Solange T. Carpes $^{g}$ \\ ${ }^{a}$ Instituto Politécnico de Castelo Branco, Portugal \\ ${ }^{\mathrm{b}}$ Centro de Biotecnologia de Plantas da Beira Interior, Castelo Branco, Portugal \\ ${ }^{\mathrm{c}}$ Centro de Estudos Florestais, Instituto Superior de Agronomia, Universidade de Lisboa, Portugal \\ d QOPNA \& LAQV-REQUIMTE, Department of Chemistry, University of Aveiro, Aveiro, Portugal \\ ${ }^{\mathrm{e}}$ Centro de Investigação de Montanha (CIMO), Instituto Politécnico de Bragança, Portugal \\ ${ }^{\mathrm{f}}$ School of Agricultural Sciences, Polytechnic Institute of Bragança, Bragança, Portugal \\ ${ }^{\mathrm{g}}$ Department of Chemistry, Federal University of Technology - Paraná (UTFPR), Pato Branco, PR, Brazil
}

\section{A R T I C L E I N F O}

\section{Keywords:}

Black pudding

Pollen

Antioxidant

Lipid oxidation

\begin{abstract}
A B S T R A C T
The antioxidant activity of bee pollen (mainly composed by Cistus ladanifer pellets) was explored in the context of black pudding production. For this purpose, three black pudding formulations comprising varying antioxidant compounds (sodium ascorbate, bee pollen and bee pollen extract) were produced.

Bee pollen was characterized according to the botanical origin, antioxidant activity, total phenol and flavonoid contents and phenolic profile. Black pudding was characterized by the microbiological safety, lipid oxidation, $\mathrm{pH}$, water activity and humidity at 1, 10, 21, 30 and 37 days. Sensory acceptance was evaluated on the four first periods of storage. Salmonella spp., Escherichia coli and Listeria monocytogenes were absent in all samples. Small variations on humidity and $\mathrm{pH}$ were observed during the black pudding's storage. Regarding lipid oxidation, it increased, on average, from $1.36 \mathrm{mg}$ to $2.11 \mathrm{mg}$ malondialdehyde $/ \mathrm{kg}$ meat. Differences among the three formulations were only significant on the first days of storage. The sensory assessment did not differ between products. This study suggests that bee pollen may be used as a natural antioxidant in meat products, yet a careful labelling is essential to alert allergic consumers.
\end{abstract}

\section{Introduction}

The safety and quality of food products are some of the main concerns of health agencies and consumers worldwide. Also, the consumers are increasingly demanding for a diverse range of food options particularly those containing biologically active ingredients with health promoting capacities and free of food additives. However, for many food products, like those containing animal derivatives, the lipid oxidation is an important source of quality deterioration, reducing their shelf lifetime and impairing its consumption (Jayawardana et al., 2011; Morrissey, Sheehy, Galvin, Kerry, \& Buckley, 1998; Shah, Bosco, \& Mir, 2014).

Black pudding is a meatless sausage containing pork blood as a main ingredient and is a product of excellence in the traditional Portuguese charcuterie called "morcela de assar". Blood sausages are produced and consumed throughout Europe and each Region reveal their own specificity and tradition. However, all black pudding are based on pork blood as its main raw material. In this case, the raw material is considered an important source of nutrients because meat derived products contain high amounts of proteins, vitamins (A, B12, and folic acid), essential minerals such as iron, zinc and selenium (Fellendorf, O'Sullivan, \& Kerry, 2017). In addition, the blood also provides an important source of proteins and lysine (Fellendorf et al., 2017).

In the central region of Portugal, the black pudding is manufactured with pork fat, pork blood, bread, onion, coriander, sugar, olive oil and salt. The shelf-life of this product commonly ranges from 20 to 30 days, although for some specific formulations it can be increased to 90 days (Silva et al., 2014).

As far as the authors know the information available in the literature regarding the black pudding produced in Portugal is scarce. However, the physicochemical and sensory characterization of Morcilla de Burgos a traditional Spanish blood sausage were studied by Santos,

\footnotetext{
* Corresponding author. Instituto Politécnico de Castelo Branco, Portugal.

E-mail address: ofelia@ipcb.pt (O. Anjos).
} 
González-Fernández, Jaime and Rovira (2003). Ramos et al. (2013) provided an important study concerning the composition and quality of different blood sausages from different countries with diverse raw materials and composition, while also plotting the importance of the mineral content in this kind of food product.

All blood sausages include antioxidants in its additive list, which allow to minimize lipid oxidation levels. However, both producers and consumers are looking for products where the synthetic antioxidants are replaced by natural ones, derived from plants. In this sense, one must highlight bee pollen as a functional food product, since this is rich in proteins, lipids, free sugars, carbohydrates, minerals, phenolic acids, flavonoids, sterols, terpenoids, carotenoids and vitamins (Bogdanov, 2011). In fact bee pollen has gained widespread attention due it's purported antioxidant (Estevinho, Dias, \& Anjos, 2019), anti-inflammatory (Maruyama, Sakamoto, Araki, \& Hara, 2010), antimutagenic (Tohamy, Abdella, Ahmed, \& Ahmed, 2014) and antimicrobial (Morais, Moreira, Feás, \& Estevinho, 2011) properties. Indeed, new applications for bee pollen are currently being developed (Almeida et al., 2017; Krystyjan, Gumul, Ziobro, \& Korus, 2015) mainly due to its use as a free radical scavenger and as lipid peroxidation inhibitor.

The aim of this study was to evaluate the shelf-life of black pudding using pollen as natural antioxidant. Therefore, different formulations of black pudding with bee pollen, bee pollen extract and synthetic antioxidant were prepared to determine oxidative stability and sensory acceptability of the final product.

\section{Material and methods}

\subsection{Chemicals}

Folin Ciocalteu phenol reagents, 2,2-diphenyl-1-picryl-hydrazyl (DPPH), gallic acid, 1,1,3,3 tetramethoxypropane (TMP) and trichloroacetic acid were obtained from Sigma Aldrich (Sternheim, Germany). Aluminum chloride, sodium carbonate, sodium erythorbate (SE), potassium acetate, ethanol, ethylenediaminetetraacetic acid (EDTA), thiobarbituric acid (TBA) and chloroform were purchased from Sigma-Aldrich (Germany) and their purities were all over 99\%. Absolute alcohol was obtained from Sigma-Aldrich (Germany). All reagents used were of analytical grade.

\subsection{Bee pollen samples}

The bee pollen samples were collected directly from local beekeepers in the spring of 2017 in Castelo Branco, Portugal and stored frozen at $-15^{\circ} \mathrm{C}$ until further analysis.

The percentage of pollen grains belonging to each botanical family was determined based on the observation of 500 pollen grains in slides prepared according the acetolise method. The observation of pollens was carried out with a Leitz microscope (Leica, DML, Wetzlar, Germany) at $\mathrm{x} 400$ and an image analysis system Qwin 500 (Leica, England).

\subsubsection{Preparation of bee pollen extract}

For the bee pollen extraction $11 \mathrm{~g}$ of fresh bee pollen was stirred in a digital shaker (VWR 15000-1 Advanced Orbital Digital Shaker) with $200 \mathrm{~mL}$ of $80 \%$ ethanol-water (v/v) at room temperature and at $4 \times g$ during $24 \mathrm{~h}$ in the dark. After this, samples were centrifuged at $4080 \times \mathrm{g}$, during $10 \mathrm{~min}$ and the supernatant was reserved. The extracts were evaporated at $40^{\circ} \mathrm{C}$ and then were frozen and lyophilized. After that the samples were stored at $-20^{\circ} \mathrm{C}$ until further analysis.

\subsubsection{Total phenolic and flavonoid compounds}

The total phenolic content (TPC) of the bee pollen extracts was determined using the Folin-Ciocalteu method as described by Moreira et al. (Moreira, Dias, Pereira, \& Estevinho, 2008) and expressed as mg of gallic acid equivalents per $\mathrm{g}$ of bee pollen (GAE/g of pollen).

For total flavonoids contents (TFC) determination in bee pollen the aluminium chloride method was used. Total flavonoids content was expressed as mg of quercetin equivalents per $\mathrm{g}$ of bee pollen $(\mathrm{QE} / \mathrm{g}$ of pollen) (Serra Bonvehí, Soliva Torrentó, \& Centelles Lorente, 2001).

\subsubsection{Identification of the phenolic compounds in bee pollen}

The major phenolic compounds of the bee pollen extracts were identified by UHPLC-DAD-ESI-MSn analysis, using a Ultimate 3000 (Dionex Co., San Jose, CA, USA) apparatus with an ultimate 3000 Diode Array Detector (Dionex Co., San Jose, CA, USA) coupled to a Thermo LTQ XL (Thermo Scientific, San Jose, CA, USA) ion trap mass spectrometer equipped with an ESI source. The chromatographic column was an Hypersil Gold (Thermo Scientific, San Jose, CA, USA) C18 column (100 mm length; $2.1 \mathrm{~mm}$ i.d.; $1.9 \mu \mathrm{m}$ particle diameter, end-capped) and the general chromatographic conditions corresponded to those previous described (Wasli, Jelali, Silva, Ksouri, \& Cardoso, 2018).

\subsubsection{Antioxidant activity of the extracts}

In order to determine the antioxidant activity of the extract of bee pollen was tested two different methods, namely DPPH and reducing power assays.

2.2.4.1. Free-radical-scavenging (DPPH) assay. The capacity to scavenge the 2,2-diphenyl-1-picrylhydrazyl (DPPH) free radical was monitored according to a method previously described by Morais et al. (Morais et al., 2011).

The extract concentrations providing $50 \%$ scavenging $\left(\mathrm{EC}_{50}\right)$ were calculated from the graph of scavenging effect percentage against extract concentration and the results were expressed as $\mathrm{mg} / \mathrm{mL}$.

2.2.4.2. Reducing power assay. Reducing power of the extracts were determined by the procedure described by Berker et al. (Berker, Güçlü, Tor, \& Apak, 2007). In this procedure, the extract concentration that providing 0.5 of absorbance $\left(\mathrm{C}_{0.5}\right)$ was calculated from the graph of absorbance registered at $700 \mathrm{~nm}$ against the correspondent extract concentration and the results were expressed as $\mathrm{mg} \mathrm{GAE} / \mathrm{mL}$.

\subsection{Black pudding samples}

The black pudding preparation was conducted under formulation and traditional procedures used in the local factory named "Salsicharia Rebolosa". Regarding producer confidentiality issues, the quantity of each ingredient is not publicised in this work, as well the quantity of pollen added.

The basic mixture of ingredients, without the commercial antioxidant, was divided into three lots. Several black puddings were performed containing three different antioxidant sources, namely: 1- fresh bee pollen; 2- lyophilized ethanolic extract of bee pollen; 3- sodium ascorbate (E301, a commercial antioxidant commonly used in the industrial process that in this study was used as control). The bee pollen (fresh and lyophilized ethanolic extract) was added dissolved in the volume of olive oil necessary for the black pudding preparation.

The black puddings for three treatments (different antioxidant sources) at five times $(0,10,21,30$ and 37 days) and in three replicates was made, totalizing 45 samples. All samples were divided in sealed polyethylene bags under vacuum and stored at $4{ }^{\circ} \mathrm{C}$ in a refrigerator. Because of the legal shelf life of the black pudding is 30 days, and because is impossible to have the results of microbiological analysis at the same data of the sensory analysis, the evaluators do not made the sensory evaluation for the 37 th days to avoid possible health risk.

\subsubsection{Microbiological analysis}

For the microbiological analysis of $L$. monocytogenes, $25 \mathrm{~g}$ of sample was homogenised for $2 \mathrm{~min}$ in $225 \mathrm{~mL}$ of Half Fraser Base CM0895 (Oxoid, Hampshire, UK), using a Stomacher 400 homogenizer (Seward, 
Basingstoke, England). The enumeration was performed according to the ISO 11290-2:1998/Amd. 1:2004(E) procedure (ISO, 1988). After incubation of the initial suspension for $1 \mathrm{~h}$ at $20^{\circ} \mathrm{C}$, a $0.1 \mathrm{~mL}$ volume was surface-inoculated on Oxoid Chromogenic Listeria Agar Base CM1084 (OCLA, Oxoid) and incubated at $37^{\circ} \mathrm{C}$ for $48 \mathrm{~h}$. The detection of $L$. monocytogenes was according to the ISO 11290-1:1996/Amd. 1:2004(E) procedure (ISO, 1996). The initial suspension was supplemented with SR0166G selective supplement (Oxoid), incubated at $30{ }^{\circ} \mathrm{C}$ for $24 \mathrm{~h}$. To the primary-enriched sample, $0.1 \mathrm{~mL}$ was streaked on OCLA and incubated at $37{ }^{\circ} \mathrm{C}$ for $48 \mathrm{~h}$, for the secondary-enriched sample, $0.1 \mathrm{~mL}$ of the same initial supplemented suspension was transferred into $10 \mathrm{~mL}$ Fraser Broth supplemented with SR0156E (Oxoid), incubated at $37^{\circ} \mathrm{C}$ for $48 \mathrm{~h}$. If no growth was detected in primary-enriched sample, $0.1 \mathrm{~mL}$ of the secondary-enriched sample was streaked on OCLA and incubated at $37^{\circ} \mathrm{C}$ for $48 \mathrm{~h}$. The colonies L. monocytogenes that grew on OCLA was green-blue surrounded by an opaque halo. The determinations per sample were carried out in duplicate and the results were expressed in CFU/g.

\subsubsection{Physicochemical analysis}

The samples were analysed for physicochemical composition (moisture, $\mathrm{pH}$ and water activity $\left(\mathrm{a}_{\mathrm{w}}\right)$ ) using standard procedures, along the storage time. Moisture content of samples, along the storage time, was quantified directly, according to the loss of mass after drying at $105^{\circ} \mathrm{C}$ in an oven (Thermo Scientific, Heratherm IMH 180) until constant weight, using AOAC procedures (AOAC, 1995). The results were expressed in percentage.

The $\mathrm{pH}$ of samples was determined weighing $10 \mathrm{~g}$ of black pudding and mixed with $100 \mathrm{~mL}$ of ultrapure water until a homogeny solution. The measurements were performed at room temperature (around $\left.24^{\circ} \mathrm{C}\right)$.

Water activity was determined by means of a Rotronic (HygroskopDT, Swiss) coupled with a Julabo (F35) thermostatized Baths.

\subsubsection{Oxidative stability - thiobarbituric acid reactive substances content (TBARS)}

In order to determine the oxidative stability of the black pudding the method of thiobarbituric acid reactive substances (TBARS) was performed according Almeida et al. (Almeida et al., 2017). Measurements were made on the day of their production and over the storage time (1, 10, 21, 30 and 37 days). Concentrations of 0.6 and $3.0 \mathrm{mmol} / \mathrm{L}$ of 1,1,3,3 tetramethoxypropane (TMP) were used as the standards. The results were expressed as $\mathrm{mg}$ of MDA/ $\mathrm{kg}$ of sample (MDA: malondialdehyde). All measurement was carried out in triplicate.

\subsubsection{Sensory analysis}

The sensory acceptance test was performed using 32 untrained assessor's usual consumers of black pudding (14 women and 8 men with ages ranging between 23 and 54 years) performed the sensory evaluation.

The sensory analyses were performed at a room temperature and the samples were presented to the panel cut as $1 \mathrm{~cm}$ thick slices of roasted black pudding, under white natural lighting (according to the International Standards (ISO, 1988). Water and apple was provided for mouth rinsing between samples.

It was made a ranking descriptive analysis (RDA) (Richter, de Almeida, Prudencio, \& de Toledo Benassi, 2010), in which the samples were presented at the same time to the panelists who had to rank the samples for the attribute aroma quality and the flavor, according to a proof sheet prepared for this specific purpose.

\subsection{Statistical analysis}

All tests were performed in triplicate and the results were presented as mean \pm standard deviation. A factorial variance analysis was performed to assess the effects of the different antioxidant used as well the shelf life period.

For each significant factor or interaction, the variance percentage was calculated and a Schefee post-hoc test with $95 \%$ confidence was applied to the corresponding variables. For the statistical analysis of the sensory data resulting from the ranking test, the Friedman's test was performed based on the sum of the ordinations assigned by the tasters. All the calculations were performed using Statistica from Statsoft (vs 7.09) (Tulsa, OK, USA).

\section{Results and discussion}

\subsection{Bee pollen characterization}

It is well know that the chemical composition of bee pollen varies depending on the plant sources, growth conditions and storage conditions (Anjos, Paula, Delgado, \& Estevinho, 2019; Atrouse, Oran, \& AlAbbadi, 2004; Bogdanov, 2011; Elamine et al., 2019; Estevinho et al., 2019; Estevinho, Rodrigues, Pereira, \& Feás, 2012; Komosinska-Vassev, Olczyk, Kaźmierczak, Mencner, \& Olczyk, 2015; Serra Bonvehí et al., 2001).

Palynological analysis found as predominant pollen Cistus ladanifer (42.6\%) followed by Echium spp. (13.6\%) and Apiaceae (13.2\%). 8.6\% of pollen of Cistaceae family were also founded. Cistus ladanifer pollen is very usual in Mediterranean regions, and in particularly in the region of the study which was well characterized previously by Raimundo et al. (Raimundo et al., 2018). The others pollen found in the mixtures were: Brassicaceae spp. (10.1\%); Cichorieae spp. (8.0\%); Asteraceae spp. (1.9\%); Lavandula spp. (1\%); Plantago spp. (0.5\%); Silene spp (0.5\%).

The values of TPC and TFC of bee pollen were $35.05 \pm 0.5 \mathrm{mg}$ $\mathrm{GAE} / \mathrm{g}$ of pollen and $6.81 \pm 0.08 \mathrm{mg} \mathrm{QE} / \mathrm{g}$ of pollen, respectively (Table 2). Our results showed a TPC higher than that observed by Morais et al. (Morais et al., 2011) that studied the honeybee-collected pollen from five Portuguese Natural Parks. They are also superior to those described by Campos et al. (Campos, Webby, Markham, Mitchell, \& da Cunha, 2003) who studied pollens from New Zealand and Portugal. Furthermore, the present values are comparable of TPC and TFC of bee pollen collected in Portugal with similar amount of Cistus ladanifer pollen (Anjos et al., 2019). The TPC of this pollen mixture were higher that the results found for the pollen mixtures used by Almeida et al. (Almeida et al., 2017) that studied the use of lyophilized bee pollen extract as a natural antioxidant source in refrigerated sausages.

Because different antioxidant agents present different mechanism for their antioxidant capacities, in this work the antioxidant activity was evaluated by two methods (DPPH and reducing power assay). On the other hand, as mentioned before, the antioxidant activity of bee pollen is well knowas well the properties of Cystus ladanifer pollen. In this work the evaluation of this property was only to calculate the quantity of bee pollen to be added in the black pudding formulation, in order to allow a similar antioxidant power of that of the commercial one.

The results of antioxidant activity of bee pollen assessed by freeradical-scavenging (DPPH) assay, expressed in terms of $\mathrm{EC}_{50}$ value, and reducing power assay are summarized in Table 2 . The $\mathrm{EC}_{50}$ values of bee pollen was $2.62 \pm 0.09 \mathrm{mg} / \mathrm{mL}$. This value indicates a good antioxidant activity and higher that the values reported by some authors (Negri, Barreto, Sper, Carvalho, \& Campos, 2018; Suriyatem R., Auras R. A., Intipunya P., 2017).

Concerning the values obtained for reducing power assay, they are also higher than those reported for Rape Bee Pollen (Sun, Guo, Zhang, \& Zhuang, 2017).

The chromatographic profile at $280 \mathrm{~nm}$ of bee pollen extract is represented in Fig. 1, while Table 1 summarizes the retention time, $\mathrm{UV}$-vis and $\mathrm{MS}^{\mathrm{n}}$ spectral data of the identified compounds. Globally, the bee pollen extract was mainly rich in myricetin and quercetin $O$ derivatives (Table 1). Please note that the presence of flavonoids such 


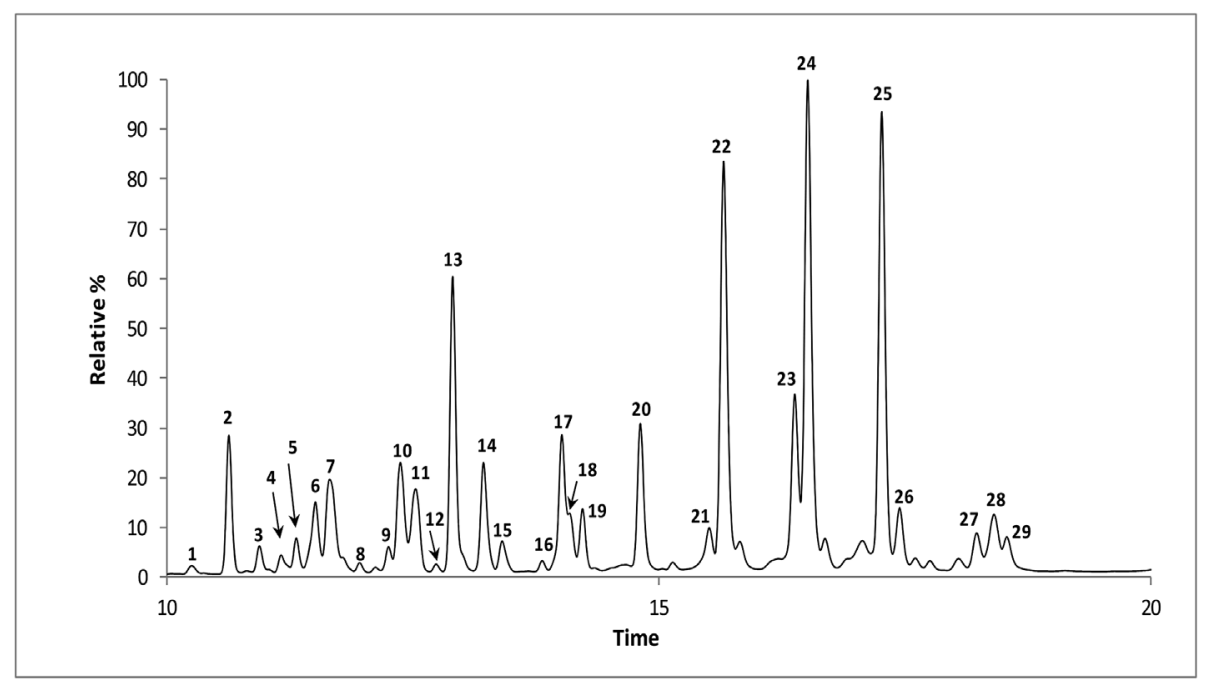

Fig. 1. Chromatographic profile at $280 \mathrm{~nm}$ of bee pollen extract. Numbers in the figure correspond to the eluted UHPLC peaks for which UV and MS data is summarized in Table 1.

as quercetin derivatives in the bee pollen has been previously related to the biological quality of the pollen, including its high antioxidant function (Lv, Wang, He, Wang, \& Suo, 2015; Serra Bonvehí et al., 2001), which is one of the main claimed advantages to the use of bee pollen as an healthy product.

\subsection{Black pudding characterization}

In all samples, Salmonella spp., Escherichia coli and Listeria monocytogenes ATCC 19117. were analysed, according the Portuguese legislation and were absent in all of them.
Table 2

TPC, TFC and antioxidant activity of bee pollen extract.

\begin{tabular}{ll}
\hline Parameters & Bee pollen \\
\hline TPC (mg GAE/g of pollen) & $35.05 \pm 0.5$ \\
TFC (mg QE/g of pollen) & $6.99 \pm 0.33$ \\
EC $_{50}(\mathrm{mg} / \mathrm{mL})$ & $2.62 \pm 0.09$ \\
Reducing power assay (mg GAE/mL) & $6.51 \pm 0.30$ \\
\hline
\end{tabular}

Table 1

UHPLC-DAD-ESI-MS $^{\mathrm{n}}$ data for bee pollen.

\begin{tabular}{|c|c|c|c|c|c|}
\hline $\mathrm{PN}$ & $t_{R}(\min )$ & $\Lambda \max (\mathrm{nm})$ & $(m / z)$ & $\mathrm{MS}^{\mathrm{n}}$ ions $(m / z)$ & Probable compound \\
\hline 1 & 10.0 & 312 & 337 & $\operatorname{MS}^{2}[337]: 173,162,191$ & coumaroyl quinic acid \\
\hline 2 & 10.3 & 258,356 & 625 & $\operatorname{MS}^{2}[625]: 316,317,271,461,479,609$ & myricetin-O-rutinoside \\
\hline \multirow[t]{2}{*}{3} & 10.7 & 264,351 & 609 & $\operatorname{MS}^{2}[609]: 447,285$ & luteolin- $O$-dihexoside \\
\hline & & & 625 & $\mathrm{MS}^{2}[625]: 301,463,445$ & quercetin-O-dihexoside \\
\hline 4 & 10.9 & 262,353 & 479 & $\operatorname{MS}^{2}[479]: 316,317$ & myricetin- $O$-hexoside \\
\hline 5 & 11.0 & 261,357 & 711 & $\operatorname{MS}^{2}[711]: 667,316,317$ & myricetin-O-(malonyl)rutinoside \\
\hline \multirow[t]{2}{*}{6} & 11.2 & 270,355 & 639 & $\mathrm{MS}^{2}[639]: 459,315$ & isorhamnetin-O-dihexoside \\
\hline & & & 595 & $\operatorname{MS}^{2}[595]: 301,463$ & quercetin- $O$-hexosyl-pentoside \\
\hline \multirow[t]{2}{*}{7} & 11.4 & $256,308,354$ & 609 & $\operatorname{MS}^{2}[609]: 301,463$ & quercetin-O-rutinoside isomer 1 \\
\hline & & & 565 & $\operatorname{MS}^{2}[565]: 521,316,317$ & myricetin-O-(malonyl)hexoside \\
\hline 8 & 11.7 & 266,353 & 609 & $\mathrm{MS}^{2}$ [609]: 301 & quercetin- $O$-rutinoside isomer 2 \\
\hline 9 & 12.0 & 266,351 & 755 & $\mathrm{MS}^{2}[755]: 609,593,573,285,255$ & luteolin-di-O-hexosyl-rhamosíde \\
\hline 10 & 12.1 & 257,353 & 695 & $\operatorname{MS}^{2}[695]: 661,609,301$ & quercetin- $O$-(malonyl)rutinoside \\
\hline 11 & 12.2 & 255,354 & 623 & $\operatorname{MS}^{2}[623]: 315,459$ & isorhamnetin- $O$-rutinoside \\
\hline 12 & 12.5 & 250 sh, 297,308 & 437 & $\mathrm{MS}^{2}[437]: 317$ & hydroxybenzoyl myricetin \\
\hline 13 & 12.6 & 256,354 & 549 & $\operatorname{MS}^{2}[549]: 505,301,463$ & quercetin-O-(malonyl)hexoside \\
\hline 14 & 13.0 & 265,350 & 679 & $\operatorname{MS}^{2}[679]: 635,301,575,255$ & quercetin derivative \\
\hline 15 & 13.2 & 257,351 & 447 & $\mathrm{MS}^{2}$ [447]: 301 & quercetin-O-rhamnoside \\
\hline 16 & 13.6 & 271,351 & 563 & $\operatorname{MS}^{2}[563]: 315,519,545$ & isorhamnetin- $O$-(malonyl)hexoside isomer 1 \\
\hline 17 & 13.8 & 256,354 & 533 & $\mathrm{MS}^{2}[533]: 489,285$ & luteolin-O-(malonyl)hexoside \\
\hline 18 & 13.8 & $\operatorname{mix}$ & 317 & $\operatorname{MS}^{2}[317]: 179,151$ & myricetin \\
\hline 19 & 14.0 & 255,353 & 563 & $\operatorname{MS}^{2}[563]: 519,315,359$ & isorhamnetin-O-(malonyl)hexoside isomer 2 \\
\hline 20 & 14.5 & 245,296 sh, 319 & 631 & $\operatorname{MS}^{2}[631]: 495,317$ & myricetin- $O$-dihydroferuloyl protocatechuic acid \\
\hline 21 & 15.2 & $245,296,310$ & 615 & $\operatorname{MS}^{2}[615]: 479 ; \operatorname{MS}^{3}[479]: 359 ; \operatorname{MS}^{4}[359]: 317$ & myricetin- $O$-acetyl hydroxybenzoyl protocatechuic acid-isomer 1 \\
\hline 22 & 15.4 & $245,296,310$ & 615 & $\operatorname{MS}^{2}[615]: 479 ; \operatorname{MS}^{3}[479]: 359 ; \operatorname{MS}^{4}[359]: 317$ & myricetin- $O$-acetyl hydroxybenzoyl protocatechuic acid isomer 2 \\
\hline 23 & 16.1 & $240,295,308$ & 599 & $\operatorname{MS}^{2}$ [599]: 463; $\operatorname{MS}^{3}[463]: 343 ; \operatorname{MS}^{4}[343]: 301$ & quercetin- $O$-acetyl hydroxybenzoyl protocatechuic acid isomer 1 \\
\hline 24 & 16.3 & $240,295,309$ & 599 & $\operatorname{MS}^{2}[599]: 479 ; \operatorname{MS}^{3}[479]: 359 ; \operatorname{MS}^{4}[359]: 317$ & myricetin-O-acetyl hydroxybenzoyl hydrobenzoic acid isomer 2 \\
\hline 25 & 17.0 & $240,295,312$ & 583 & $\mathrm{MS}^{2}$ [583]: 463; $\mathrm{MS}^{3}$ [463]: 343; $\mathrm{MS}^{4}[343$ ]: 301 & quercetin- $O$-acetyl hydroxybenzoyl hydrobenzoic acid isomer 1 \\
\hline 26 & 17.2 & $240,295,308$ & 583 & $\operatorname{MS}^{2}[583]: 463 ; \operatorname{MS}^{3}[463]: 343 ; \operatorname{MS}^{4}[343]: 301$ & quercetin- $O$-acetyl hydroxybenzoyl hydrobenzoic acid isomer 2 \\
\hline $27-29$ & $17.8-18.4$ & $242,270-294$ & 785 & $\begin{array}{l}\operatorname{MS}^{2}[785]: 665 ; \operatorname{MS}^{3}[665]: 545 ; \operatorname{MS}^{4}[545]: 503,459 \\
399\end{array}$ & $O$-dihydroxybenzoyl acetyl malonyl coumaric acid flavonoid derivative \\
\hline
\end{tabular}

Peak numbers (PN) correspond to those depicted in Fig. 1. 
Table 3

Chemical analysis of different formulation of black pudding.

\begin{tabular}{|c|c|c|c|c|}
\hline & \multicolumn{4}{|c|}{ Treatment } \\
\hline & Days & E301 & Pollen & Pollen extract \\
\hline \multirow[t]{5}{*}{$\mathrm{pH}$} & 1 & $6.75 \pm 0.02^{\mathrm{bB}}$ & $6.70 \pm 0.01^{\mathrm{aA}}$ & $6.68 \pm 0.01^{\mathrm{aA}}$ \\
\hline & 10 & $6.72 \pm 0.01^{\mathrm{bB}}$ & $6.75 \pm 0.01^{\mathrm{bC}}$ & $6.72 \pm 0.00^{\mathrm{aA}}$ \\
\hline & 21 & $6.60 \pm 0.02^{\mathrm{cA}}$ & $6.80 \pm 0.01^{\mathrm{cB}}$ & $6.59 \pm 0.04^{\mathrm{bA}}$ \\
\hline & 30 & $6.55 \pm 0.02^{\mathrm{aA}}$ & $6.77 \pm 0.02^{\mathrm{bC}}$ & $6.61 \pm 0.02^{\mathrm{bB}}$ \\
\hline & 37 & $6.51 \pm 0.01^{\mathrm{aA}}$ & $6.71 \pm 0.02^{\mathrm{aC}}$ & $6.66 \pm 0.01^{\mathrm{aB}}$ \\
\hline \multirow{5}{*}{$\begin{array}{l}\text { Moisture content } \\
\text { (\%) }\end{array}$} & 1 & $48.53 \pm 0.22^{\mathrm{aA}}$ & $48.87 \pm 0.14^{\mathrm{bA}}$ & $48.63 \pm 0.19^{\mathrm{abA}}$ \\
\hline & 10 & $49.07 \pm 0.28^{\mathrm{aB}}$ & $46.54 \pm 0.43^{\mathrm{aA}}$ & $48.66 \pm 0.28^{\mathrm{abB}}$ \\
\hline & 21 & $47.93 \pm 0.73^{\mathrm{aB}}$ & $46.33 \pm 0.59^{\mathrm{aA}}$ & $49.73 \pm 0.08^{\mathrm{bC}}$ \\
\hline & 30 & $48.39 \pm 0.48^{\mathrm{aB}}$ & $46.47 \pm 0.44^{\mathrm{aA}}$ & $48.10 \pm 0.89^{\mathrm{aAB}}$ \\
\hline & 37 & $48.50 \pm 0.34^{\mathrm{aA}}$ & $47.16 \pm 0.30^{\mathrm{aB}}$ & $48.56 \pm 0.31^{\mathrm{abA}}$ \\
\hline \multirow[t]{5}{*}{ Water activity } & 1 & $0.92 \pm 0.01^{\mathrm{dA}}$ & $0.92 \pm 0.01^{\mathrm{bA}}$ & $0.92 \pm 0.03^{\mathrm{bA}}$ \\
\hline & 10 & $0.90 \pm 0.01^{\mathrm{bA}}$ & $0.92 \pm 0.01^{\mathrm{bC}}$ & $0.91 \pm 0.01^{\mathrm{aB}}$ \\
\hline & 21 & $0.91 \pm 0.01^{\mathrm{cA}}$ & $0.91 \pm 0.01^{\mathrm{aA}}$ & $0.91 \pm 0.01^{\mathrm{aA}}$ \\
\hline & 30 & $0.89 \pm 0.01^{\mathrm{aA}}$ & $0.91 \pm 0.02^{\mathrm{aA}}$ & $0.92 \pm 0.05^{\mathrm{bA}}$ \\
\hline & 37 & $0.92 \pm 0.02^{\mathrm{cA}}$ & $0.92 \pm 0.01^{\mathrm{bA}}$ & $0.92 \pm 0.01^{\mathrm{bA}}$ \\
\hline \multirow{5}{*}{$\begin{array}{l}\text { TBARS (mg of } \\
\text { MDA/kg of } \\
\text { black } \\
\text { pudding) }\end{array}$} & 1 & $1.30 \pm 0.08^{\mathrm{aA}}$ & $2.56 \pm 0.30^{\mathrm{aB}}$ & $3.02 \pm 0.13^{\mathrm{aC}}$ \\
\hline & 10 & $1.28 \pm 0.02^{\mathrm{aA}}$ & $2.21 \pm 0.23^{\mathrm{aB}}$ & $2.46 \pm 0.24^{\mathrm{bB}}$ \\
\hline & 21 & $1.24 \pm 0.15^{\mathrm{aA}}$ & $1.33 \pm 0.16^{\mathrm{bA}}$ & $1.32 \pm 0.06^{\mathrm{cA}}$ \\
\hline & 30 & $1.15 \pm 0.07^{\mathrm{aA}}$ & $1.34 \pm 0.10^{\mathrm{bA}}$ & $1.27 \pm 0.07^{\mathrm{cA}}$ \\
\hline & 37 & $1.13 \pm 0.06^{\mathrm{aA}}$ & $1.30 \pm 0.15^{\mathrm{bA}}$ & $1.50 \pm 0.06^{\mathrm{cB}}$ \\
\hline
\end{tabular}

E301- sodium ascorbate. Different lower-case letter in the same column indicate significant difference $(\mathrm{P}<0.05)$ by Scheffe test. Different capital letters in the same row indicate significant difference $(\mathrm{P}<0.05)$ by Tukey's test.

Table 4

Component variance analysis for the measured parameter of black pudding considered the threes treatment and the 5 storage period.

\begin{tabular}{llllll}
\hline \multirow{2}{*}{ pH } & Variance origin & DF & F & p & Variance percentage \\
\hline \multirow{5}{*}{ Moisture } & Treatment (T) & 2 & 234.1 & $0.0000^{* * *}$ & 37.8 \\
& Days (D) & 4 & 59.4 & $0.0000^{* * *}$ & 15.8 \\
& TxD & 8 & 55.2 & $0.0000^{* * *}$ & 44.0 \\
& Residual & 30 & & & 2.4 \\
& Treatment (T) & 2 & 63.2 & $0.0000^{* * *}$ & 48.0 \\
\multirow{4}{*}{ Water activity } & Days (D) & 4 & 6.4 & $0.0007^{* * *}$ & 7.0 \\
& TxD & 8 & 9.7 & $0.0000^{* * *}$ & 33.4 \\
& Residual & 30 & & & 11.6 \\
& Treatment (T) & 2 & 276.3 & $0.157^{\text {n.s. }}$ & - \\
TBARS & Days (D) & 4 & 196.7 & $0.064^{\text {n.s. }}$ & - \\
& TxD & 8 & 116.8 & $0.281^{\text {n.s. }}$ & - \\
& Residual & 30 & & & \\
& Treatment (T) & 2 & 149.8 & $0.0000^{* * *}$ & 25.7 \\
& Days (D) & 4 & 156.1 & $0.0000^{* * *}$ & 44.7 \\
& TxD & 8 & 32.3 & $0.0000^{* * *}$ & 27.0 \\
& Residual & 30 & & & 2.6 \\
\hline
\end{tabular}

DF - degrees of freedom; n.s. - not significant, p > 0.05; * Significant, $0.01<\mathrm{p}<0.05 ; * *$ very significant, $0.001<\mathrm{p}<0.01 ; * * *$ highly significant, $\mathrm{p}<0.001$.

The results obtained for the $\mathrm{pH}$, moisture content, water activity and lipid oxidation by TBARS analysis during the storage period of black pudding are presented in Table 3. Overall, the $\mathrm{pH}$ of black pudding samples were similar to those studied by Santos et al. (Santos et al., 2003) and higher to those found by Diez et al. (Diez, Santos, Jaime, \& Rovira, 2008) that studied blood sausages produced with rice. The $\mathrm{pH}$ of the different formulations of black puddings was influenced by the antioxidant added and the storage period (Table 3). The higher values are found for the black puddings produced with bee pollen as antioxidant, and the variations during the time was different for the different formulation ( $\mathrm{TxD}=44.0^{* * *}$, Table 4). These variations could be explained by the fact that the bee pollen have a lower $\mathrm{pH}$ than black pudding. According to Anjos et al. (Anjos et al., 2019) the pH of pollen ranging between 3.4 and 5.9. The $\mathrm{pH}$ of the pollen used in the present study was $4.70 \pm 0.47$.

Moisture content of black pudding depends on the fat content and the final preservation process: cooked, dried or smoked (Ramos et al., 2013, pp. 93-111). The moisture content of studied products ranged, on average, between $46.33 \%$ and $49.73 \%$. The different treatments and storage days were significant factors explaining $48 \%$ and $7 \%$ of the total variance, respectively, regardless variability between samples also had a high impact (explaining $11.6 \%$ of the total variance). The lower moisture content was observed for the black pudding made with pollen and the higher values for the black pudding made with pollen extract. Our values are lower than those observed by Fellendorf et al. (Fellendorf et al., 2017) that studied black puddings usually consumed in Ireland and the United Kingdom. Differences can however be due to the distinct list of ingredients among the formulations.

$\mathrm{a}_{\mathrm{w}}$ is a feature of great importance in food products preservation and particularly in black pudding that was produced with meat and blood. During the manufacturing process of these products they were subjected to high temperatures and, as expected, vegetative cells do not survive, but after the high temperatures process, post-contamination of the product may occur. The higher values of $a_{w}$ for these kind of products are always higher (Santos et al., 2003) and because of that it is very important to performed a restrict quality control. Our values for $\mathrm{a}_{\mathrm{w}}$, ranging between 0.90 and 0.92 , were lower than those observed in other studies (Santos et al., 2003). For this parameter, no significant differences were found among the sausages formulations neither along the storage period (Table 4).

TBARS is generally used as an indicator of the degree of lipid oxidation for pork meat and pork meat sausages, that reflects the content of MDA formed during the oxidation of polyunsaturated fatty acids (Tang, Sheehan, Buckley, Morrissey, \& Kerry, 2001).

Concerning the TBARS, Selani et al. (Selani et al., 2011) refer that values lower than $3 \mathrm{mg}$ of MDA $/ \mathrm{kg}$ sample can be considered in good condition. All the black pudding samples analysed could be considered in good condition during all storage periods (values lower $2.56 \mathrm{mg}$ MDA/kg sample) (Table 3). In the first day, the sample prepared with pollen extract had a value of $3.04 \mathrm{mg}$ MDA $/ \mathrm{kg}$ of black pudding. The black pudding prepared with pollen as natural antioxidant had values similar to those observed for the black pudding prepared with the commercial antioxidants, except for the first 15 days after production. Further studies may be performed in order to evaluate the optimum quantity of pollen.

For TBARS all factors are highly significant, but the stored days were the most important and explain $44.7 \%$ of the total variance. The variation between days was also different for the different antioxidants used. The bee pollen presents a similar antioxidant effect than the commercial product.

\subsection{Sensory evaluation}

The sensory evaluation of the 12 black pudding products is plot in Fig. 2.

The black pudding was sensory analysed only until 30 days, because it corresponds to the legal shelf-life in the factory. According Silva et al. (Silva et al., 2014), after 30 days of storage, the over-wrap packed blood sausages present mould and yeast. Nevertheless, for the vacuumpacked blood sausages, the mould and yeast appears only after 45 days (Silva et al., 2014). In our study we use the vacuum-packed system but because no studies were performed in this product to extend the shelflife we only consider the legal limit (30 days) stablished for this product for sensory analysis, excluding for this propose the samples with 37 day of shelf-life. In fact, the microbiological results confirm that no mould or yeast have been developed in the samples, so it was need future research in other to establish better the shelf-life of the product.

The ANOVA made for all samples and for the appearance and flavor revealed that no significant difference exists for the storage period (appearance: $\mathrm{p}=1.000$; flavour: $\mathrm{p}=0.999$ ) and for the different formulation period (appearance: $\mathrm{p}=0.328$; flavor: $\mathrm{p}=0.235$ ). These results confirm that the new additives, pollen or pollen extract, do not 

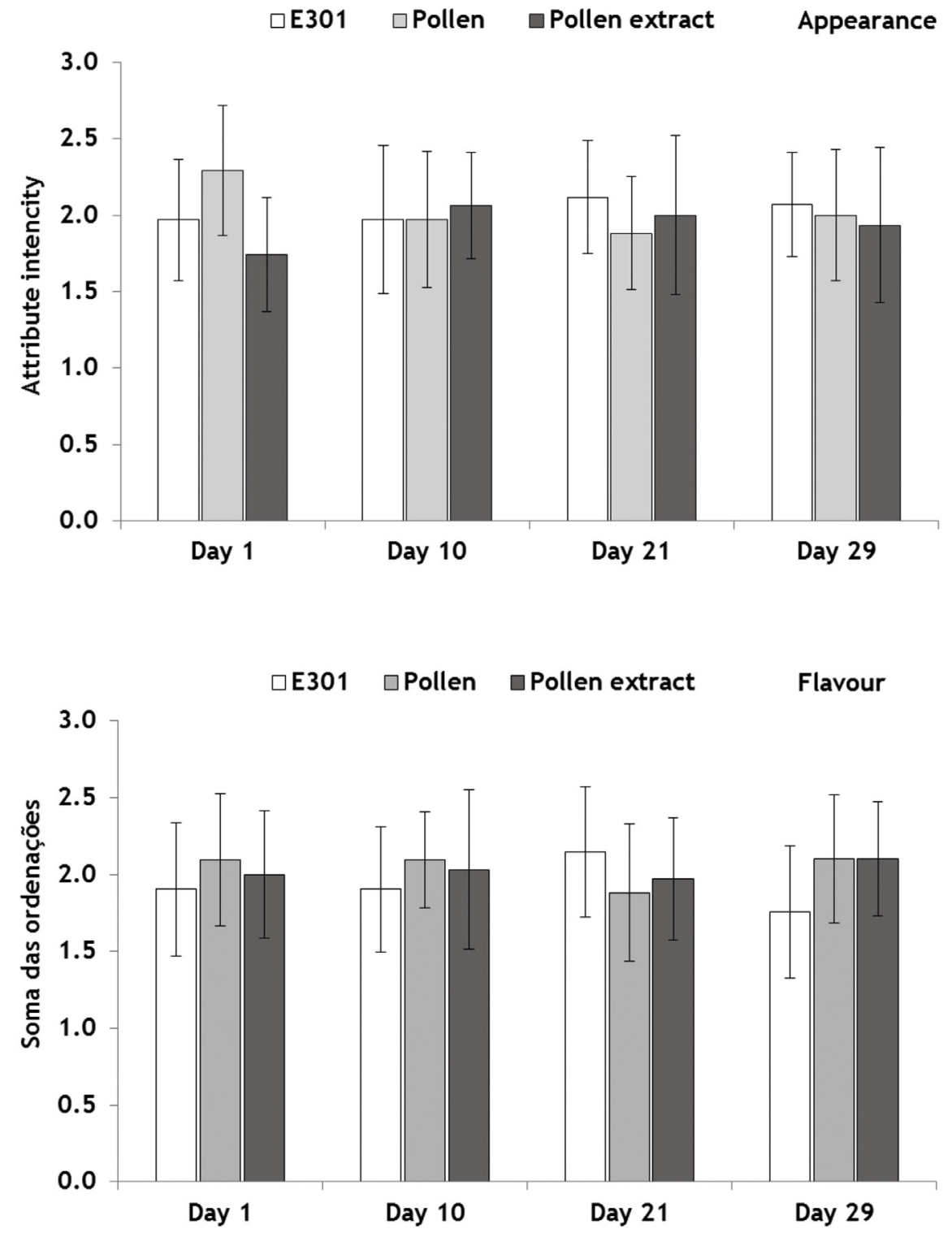

Fig. 2. Appearance and flavour evaluation by sensory analysis of black pudding shelf-life.

affect the preference of the consumers.

Many of the tasters referred that the forced choice required by the triangular test was very difficult because the tree samples were very similar ( $24 \%$ of the tasters). Other comments given by the tasters that helped them to identify some differences were: homogeneity of the product (18\%); visible pieces of onion (5\%) and more fat quantity in a specific sample (3\%). However, this kinds of comments are all related to manufacture process of this product. The different raw materials are cut in small pouches and mixed but not crushed.

\section{Conclusion}

The inclusion of bee pollen as an antioxidant could be a natural alternative to prevent the lipid oxidation in black pudding. These products could be added dissolved in the olive oil during preparation of the sausage and have the advantage to be a recognized healthy food product.

Additionally, the use of bee pollen as antioxidant improves the product quality and consumer acceptance and do not affect their traditional flavor.

Furthermore, it is important to note that the use of bee pollen must be very well mentioned in the label, to prevent allergic risks. More studies will be need in order to identify the more appropriate concentration of bee pollen to use as well the influence of botanical origin of bee pollen.

\section{Declarations of interest}

None.

\section{Acknowledgments}

Centro de Estudos Florestais that is a research unit funded by FCT (UID/AGR/00239/2019).

The author Estevinho M. L. wishes to thank to the strategic programme UID/BIA/04050/2013(POCI-01-0145-FEDER-007569) funded by national funds through the Fundação para a Ciência e a Tecnologia (FCT, Portugal) and by the European Regional Development Fund (ERDF) through the COMPETE2020-Programa Operacional Competitividade e Internacionalização (POCI).

Thanks are also due to FCT/MEC for the financial support to the research unit QOPNA (FCT UID/QUI/00062/2019), through national 
founds and where applicable co-financed by FEDER, within PT2020 Partnership Agreement. Susana Cardoso thanks the research contract under the project AgroForWealth (CENTRO-01-0145-FEDER-000001), funded by Centro2020, through FEDER and PT2020.

\section{References}

Almeida, J. de F., Reis, A. S. dos, Heldt, L. F. S., Pereira, D., Bianchin, M., Moura, C.de, et al. (2017). Lyophilized bee pollen extract: A natural antioxidant source to prevent lipid oxidation in refrigerated sausages. LWT - Food Science and Technology, 76, 299-305. http://doi.org/10.1016/j.lwt.2016.06.017.

Anjos, O., Paula, V., Delgado, T., \& Estevinho, L. (2019). Influence of the storage conditions on the quality of bee pollen. Zemdirbyste-Agriculture, 106(1), 87-94. http:// doi.org/10.13080/z-a.2019.106.012.

AOAC (1995). Official methods of analysis (16th ed.). Arlington, VA, USA: Association of Official Analytical Chemists.

Atrouse, O. M., Oran, S. A., \& Al-Abbadi, S. Y. (2004). Chemical analysis and identification of pollen grains from different jordanian honey samples. International Journal of Food Science and Technology, 39(4), 413-417. http://doi.org/10.1111/j.13652621.2004.00798.x.

Berker, K. I., Güçlï, K., Tor, İ., \& Apak, R. (2007). Comparative evaluation of Fe(III) reducing power-based antioxidant capacity assays in the presence of phenanthroline, batho-phenanthroline, tripyridyltriazine (FRAP), and ferricyanide reagents. Talanta, 72(3), 1157-1165. http://doi.org/10.1016/j.talanta.2007.01.019.

Bogdanov, S. (2011). Pollen: Nutrition, functional properties, health: A review. In B. P. Science (Ed.). Bee product science. Retrieved from http://www.bee-hexagon.net/files/ file/fileE/Health/PollenBook2Review.pdf.

Campos, M. G., Webby, R. F., Markham, K. R., Mitchell, K. A., \& da Cunha, A. P. (2003). Age-Induced diminution of free radical scavenging capacity in bee pollens and the contribution of constituent flavonoids. Journal of Agricultural and Food Chemistry, 51(3), 742-745. http://doi.org/10.1021/jf0206466.

Diez, A. M., Santos, E. M., Jaime, I., \& Rovira, J. (2008). Application of organic acid salts and high-pressure treatments to improve the preservation of blood sausage. Food Microbiology, 25(1), 154-161. http://doi.org/10.1016/j.fm.2007.06.004.

Elamine, Y., Lyoussi, B., Anjos, O., Estevinho, L. M., Aazza, S., Carlier, J. D., et al. (2019). Zantaz honey "monoflorality": Chemometric applied to the routinely assessed parameters. LWT. http://doi.org/10.1016/j.lwt.2019.02.039.

Estevinho, L. M., Dias, T., \& Anjos, O. (2019). Influence of the storage conditions (frozen vs dried) in health-related lipid indexes and antioxidants of bee pollen. European Journal of Lipid Science and Technology, 121(2), 1800393. 9 pages http://doi.org/10. 1002/ejlt.201800393.

Estevinho, L. M., Rodrigues, S., Pereira, A. P., \& Feás, X. (2012). Portuguese bee pollen: Palynological study, nutritional and microbiological evaluation. International Journal of Food Science \& Technology, 47(2), 429-435. http://doi.org/10.1111/j.1365-2621. 2011.02859.x.

Fellendorf, S., O'Sullivan, M. G., \& Kerry, J. P. (2017). Effect of different salt and fat levels on the physicochemical properties and sensory quality of black pudding. Food Science \& Nutrition, 5(2), 273-284. http://doi.org/10.1002/fsn3.390.

ISO (1988). Sensory analysis. General guidance for the design of test rooms. Ref. no. Genève, Switzerland: International Organization for Standardization ISO 8589:1988.

ISO (1996). 11290-1:1996/Amd 1:2004. Modification of the isolation media and the haemolysis test, and inclusion of precision data. Modification of the isolation media and the haemolysis test, and inclusion of precision data.

Jayawardana, B. C., Hirano, T., Han, K. H., Ishii, H., Okada, T., Shibayama, S., et al. (2011). Utilization of adzuki bean extract as a natural antioxidant in cured and un cured cooked pork sausages. Meat Science, 89(2), 150-153. http://doi.org/10.1016/j. meatsci.2011.04.005.

Komosinska-Vassev, K., Olczyk, P., Kaźmierczak, J., Mencner, L., \& Olczyk, K. (2015). Bee pollen: Chemical composition and therapeutic application. Evidence-based Complementary and Alternative Medicine, 2015, 1-6. http://doi.org/10.1155/2015/ 297425.

Krystyjan, M., Gumul, D., Ziobro, R., \& Korus, A. (2015). The fortification of biscuits with bee pollen and its effect on physicochemical and antioxidant properties in biscuits. LWT - Food Science and Technology, 63(1), 640-646. http://doi.org/10.1016/j.lwt. 2015.03.075.

Lv, H., Wang, X, He, Y, Wang, H., \& Suo, Y. (2015). Identification and quantification of flavonoid aglycones in rape bee pollen from Qinghai-Tibetan Plateau by HPLC-DADAPCI/MS. Journal of Food Composition and Analysis, 38, 49-54. http://doi.org/10. 1016/j.jfca.2014.10.011.

Maruyama, H., Sakamoto, T., Araki, Y., \& Hara, H. (2010). Anti-inflammatory effect of bee pollen ethanol extract from Cistus sp. of Spanish on carrageenan-induced rat hind paw edema. BMC Complementary and Alternative Medicine, 10(1), 30. http://doi.org/ 10.1186/1472-6882-10-30.

Morais, M., Moreira, L., Feás, X., \& Estevinho, L. M. (2011). Honeybee-collected pollen from five Portuguese Natural Parks: Palynological origin, phenolic content, antioxidant properties and antimicrobial activity. Food and Chemical Toxicology, 49(5), 1096-1101. http://doi.org/10.1016/j.fct.2011.01.020.

Moreira, L., Dias, L. G., Pereira, J. A., \& Estevinho, L. (2008). Antioxidant properties, total phenols and pollen analysis of propolis samples from Portugal. Food and Chemical Toxicology, 46(11), 3482-3485. http://doi.org/10.1016/j.fct.2008.08.025.

Morrissey, P. A., Sheehy, P. J. A., Galvin, K., Kerry, J. P., \& Buckley, D. J. (1998). Lipid stability in meat and meat products. Meat Science, 49, S73-S86. http://doi.org/10. 1016/S0309-1740(98)90039-0.

Negri, G., Barreto, L. M. R. C., Sper, F. L., Carvalho, C. de, Campos, M., \& das, G. R. (2018). Phytochemical analysis and botanical origin of Apis mellifera bee pollen from the municipality of Canavieiras, Bahia State, Brazil. Brazilian Journal of Food Technology, 21(2), e57566. http://doi.org/10.1590/1981-6723.17616.

Raimundo, J. R., Frazão, D. F., Domingues, J. L., Quintela-Sabarís, C., Dentinho, T. P., Anjos, O., et al. (2018). Neglected mediterranean plant species are valuable resources: The example of Cistus ladanifer. Planta, 248(6), 1351-1364. http://doi.org/ 10.1007/s00425-018-2997-4.

Ramos, D. D., Villalobos-delgado, L. H., Cabeza, E. A., Caro, I., Fernández-diez, A., \& Mateo, J. (2013). Mineral composition of blood sausages - a two-case study. January http://doi.org/10.5772/53591.

Richter, V. B., de Almeida, T. C. A., Prudencio, S. H., \& de Toledo Benassi, M. (2010) Proposing a ranking descriptive sensory method. Food Quality and Preference, 21(6), 611-620. http://doi.org/10.1016/j.foodqual.2010.03.011.

Santos, E. M., González-Fernández, C., Jaime, I., \& Rovira, J. (2003). Physicochemica and sensory characterisation of Morcilla de Burgos, a traditional Spanish blood sausage. Meat Science, 65(2), 893-898. http://doi.org/10.1016/S0309-1740(02 00296-6.

Selani, M. M., Contreras-Castillo, C. J., Shirahigue, L. D., Gallo, C. R., Plata-Oviedo, M., \& Montes-Villanueva, N. D. (2011). Wine industry residues extracts as natural antioxidants in raw and cooked chicken meat during frozen storage. Meat Science, 88(3), 397-403. http://doi.org/10.1016/j.meatsci.2011.01.017.

Serra Bonvehí, J., Soliva Torrentó, M., \& Centelles Lorente, E. (2001). Evaluation of polyphenolic and flavonoid compounds in honeybee-collected pollen produced in Spain. Journal of Agricultural and Food Chemistry, 49(4), 1848-1853. Retrieved from http://www.ncbi.nlm.nih.gov/pubmed/11308335.

Shah, M. A., Bosco, S. J. D., \& Mir, S. A. (2014). Plant extracts as natural antioxidants in meat and meat products. Meat Science, 98(1), 21-33. http://doi.org/10.1016/j. meatsci.2014.03.020.

Silva, F. A. P., Amaral, D. S., Guerra, I. C. D., Arcanjo, N. M. O., Bezerra, T. K. A., Ferreira, V. C. S., et al. (2014). Shelf life of cooked goat blood sausage prepared with the addition of heart and kidney. Meat Science, 97(4), 529-533. http://doi.org/10.1016/ j.meatsci.2014.03.018

Sun, L., Guo, Y., Zhang, Y., \& Zhuang, Y. (2017). Antioxidant and anti-tyrosinase activities of phenolic extracts from rape bee pollen and inhibitory melanogenesis by cAMP/MITF/TYR pathway in B16 mouse melanoma cells. Frontiers in Pharmacology, 8http://doi.org/10.3389/fphar.2017.00104.

Suriyatem, R., Auras, R. A., \& Intipunya, P. R. P. (2017). Predictive mathematical modeling for EC50 calculation of antioxidant activity and antibacterial ability of Thai bee products. Journal of Applied Pharmaceutical Science. http://doi.org/10.7324/JAPS. 2017.70917

Tang, S., Sheehan, D., Buckley, D. J., Morrissey, P. A., \& Kerry, J. P. (2001). Anti-oxidant activity of added tea catechins on lipid oxidation of raw minced red meat, poultry and fish muscle. International Journal of Food Science and Technology, 36(6), 685-692. http://doi.org/10.1046/j.1365-2621.2001.00497.x.

Tohamy, A. A., Abdella, E. M., Ahmed, R. R., \& Ahmed, Y. K. (2014). Assessment of antimutagenic, anti-histopathologic and antioxidant capacities of Egyptian bee pollen and propolis extracts. Cytotechnology, 66(2), 283-297. http://doi.org/10.1007/ s10616-013-9568-0.

Wasli, H., Jelali, N., Silva, A. M. S., Ksouri, R., \& Cardoso, S. M. (2018). Variation of polyphenolic composition, antioxidants and physiological characteristics of dill (Anethum graveolens L.) as affected by bicarbonate-induced iron deficiency conditions. Industrial Crops and Products, 126, 466-476. http://doi.org/10.1016/j.indcrop. 2018.10.007. 